\title{
Bufalin Inhibits hTERT Expression and Colorectal Cancer Cell Growth by Targeting CPSF4
}

\author{
Ningning Zhang ${ }^{a}$ Yunpeng Xie ${ }^{a}$ Yidi Tai ${ }^{a}$ Yingying Gao ${ }^{a}$ Wei Guo ${ }^{a}$ Wendan Yu ${ }^{a}$ \\ Jia Lia Xu Fenga Jiaojiao Hao ${ }^{a}$ Yue Gao Xinrui Zhao ${ }^{a}$ Yina Liao ${ }^{a}$ Wei Jiang ${ }^{a}$ \\ Ge Liu ${ }^{a}$ Wuguo Deng ${ }^{b}$ Xiaonan Cuia \\ aThe First Affiliated Hospital \& Institute of Cancer Stem Cell, Dalian Medical University, Dalian, China; \\ bSun Yat-sen University Cancer Center, State Key Laboratory of Oncology in South China, Collaborative \\ Innovation Center for Cancer Medicine, Guangzhou, China
}

\section{Key Words}

Bufalin • hTERT • CPSF4 • Proliferation • Apoptosis • Migration

\begin{abstract}
Background/Aims: Bufalin can induce apoptosis in certain human cancer cell lines, but bufalin has not yet been thoroughly evaluated in colorectal cancer cells. Cleavage and polyadenylation specific factor 4 (CPSF4) and human telomerase reverse transcriptase (hTERT) play important roles in colorectal cancer growth. The aim of this study was to investigate the roles and interactions of bufalin, CPSF4 and hTERT and the effects of bufalin in human colorectal cancer. Methods: We treated LoVo and SW620 cells with bufalin to investigate the effect of bufalin on proliferation, apoptosis and migration. We verified the relationship between CPSF4 and hTERT using pulldown assays, luciferase reporter assays and chromatin immunoprecipitation (ChIP) assays. Results: Bufalin inhibited the proliferation and migration of and induced apoptosis in LoVo and SW620 cells. We identified CPSF4 as an hTERT promoter-binding protein in colorectal cancer cells. Conclusion: Our study identified bufalin as a potential small molecule inhibitor for cancer therapy.

\section{Introduction}

Colorectal cancer (CRC) is one of the most common malignancies and the third most common cause of cancer-related mortality in the world [1]. Additionally, CRC is becoming the fastest growing cancer in our society [2].

"Huachansu," an injectable form of Chan Su in a physiological saline solution, has been officially approved as a regimen for cancer therapy in China [3]. The anticancer activity of "huachansu" could be attributed to its three major components, bufalin, resibufogenin, and 
cinobufagin. Bufalin is the major component of the Chinese medicine "Chan Su." It is an extract of dried toad venom from the skin glands of Bufo gargarizans or Bufo melanostictus. Bufalin can inhibit the proliferation of transplanted human hepatocellular carcinoma in nude mice [4] and induce apoptosis in certain human cancer cell lines, including prostate cancer [5], leukemia [6], osteosarcoma [7, 8], gastric cancer [9] and colorectal cancer [10], and induces autophagy in human colon cancer cells through reactive oxygen species generation and JNK activation [11]. Additionally, bufalin can inhibit angiogenesis and regulate miR-497 expression, and bufalin and miR-497 act in synergy to inhibit colorectal cancer metastasis [12]. However, the effect of bufalin on colorectal cancer cells has not thoroughly been evaluated.

Telomerase, which is a nuclear ribonucleoprotein enzyme complex, carries its own templates and maintains its telomere length by synthesizing telomeric DNA repeats. The activity of telomerase may be linked to the processes of governing cellular immortalization and senescence $[13,14]$. Telomerase activity is very high in human cancer cells, but it is absent in most normal human cells [15]. Research has demonstrated that colorectal adenocarcinoma exhibits high levels of telomerase activity $[16,17]$, and human telomerase reverse transcriptase (hTERT) has been identified as a potential biomarker for CRC [18]. Massive cell death results when telomerase is inhibited in actively dividing tumor cells [19]; however, the regulatory processes governing the activation and expression levels of telomerase remain areas of active research.

Cleavage and polyadenylation specific factor 4 (CPSF4), a member of the CPSF complex, was originally discovered as an essential component of the 3 ' end processing machinery of cellular pre-mRNAs. [20]. CPSF4 may be a potential prognostic biomarker and therapeutic target for lung adenocarcinoma [21]. The role of CPSF4 as a transcriptional coactivator has also been reported [22]. CPSF4 can bind to cyclooxygenase (COX-2) promoter sequences directly and activate the transcription of COX-2 [23]. Although the function of CPSF4 has been examined in different model systems, its potential role in tumors has not been fully investigated due to a lack of data regarding CPSF4 expression and tumor cell growth in colorectal cancer cells. Because CPSF4 protein promotes the expression of hTERT and telomerase activity in lung cancer cell lines, we investigated whether CPSF4 protein promotes the expression of hTERT in colorectal cancer cell lines [24].

Based on the above reports, we used SW620 and LoVo cells as the experimental model to verify our hypothesis. Our results showed that bufalin could decrease the expression of hTERT by inhibiting CPSF 4 and modulate the expression of apoptosis, proliferation and EMT related proteins, inducing apoptosis, and inhibit proliferation and EMT, suggesting its potential application in colorectal cancer therapy.

\section{Methods and Materials}

Materials and Cell culture

Bufalin was obtained from Sigma (St. Louis, MO) and dissolved in DMSO. SW620 and LoVo cells were obtained from the American Type Culture Collection. SW620 cells were cultured in Dulbecco's modified Eagle medium (HyClone, Logan, UT, USA). LoVo cells were cultured in Roswell Park Memorial Institute (RPMI) 1640 medium (HyClone, Logan, UT, USA). All of the cells were supplemented with 10\% fetal bovine serum (FBS) (HyClone, Logan, UT, USA) and were maintained in a humidified atmosphere with $5 \% \mathrm{CO}_{2}$ at $37^{\circ} \mathrm{C}$.

\section{Cell Proliferation Assay}

Cell proliferation was detected by a Cell Counting Kit-8 assay. The cells were suspended in medium supplemented with $10 \%$ heat-inactivated fatal bovine serum and subsequently seeded in 96 -well plates and incubated for $24 \mathrm{~h}$. Then, the plates were divided into several groups treated with different concentrations. Then, the plates were incubated for 1, 2, 3 and 4 days. After incubation, $10 \mu$ l of CCK-8 solution was added to each well and incubated at $37^{\circ} \mathrm{C}$ for an additional $2 \mathrm{~h}$. Optical density (OD) value of absorbance at $450 \mathrm{~nm}$ 


\section{Cellular Physiology Cell Physiol Biochem 2016;40:1559-1569 \begin{tabular}{l|l|l} 
and Biochemistry.1159/000453206 & $\begin{array}{l}\text { (c) 2016 The Author(s). Published by S. Karger AG, Basel } \\
\text { www.karger.com/cpb }\end{array}$
\end{tabular} \\ Zhang et al.: Bufalin Inhibits Colorectal Cancer Cells Growth}

was measured with a Thermo Scientific Fluoroskan Ascent FL. The results were plotted as the means \pm SEM of three independent experiments with three determinations per sample for each experiment.

Western blotting

Cells were washed in PBS before incubation with lysis buffer (1\% Triton X-100, $150 \mathrm{mM} \mathrm{NaCl}, 10$ mM Tris, pH 7.4, 1 mM EDTA, 1 mM EGTA, pH 8.0, 0.2 mM Na3V04, 0.2 mM phenylmethylsulfonyl fluoride, $0.5 \%$ Nonidet P-40) on ice for $10 \mathrm{~min}$. The cell lysates were centrifuged at 9,000 $\mathrm{g}$ for $15 \mathrm{~min}$, and the supernatants were collected. The protein concentration was determined with the Coomassie Protein Assay reagent using bovine serum albumin (BSA) as a standard. Equal amounts of protein extracts (30 $\mu \mathrm{g})$ were separated by $12 \%$ sodium dodecyl sulfate (SDS)-polyacrylamide gel electrophoresis (PAGE) and transferred to nitrocellulose filter (NC) membranes. The membranes were blocked in 5\% non-fat milk in Tris-buffered saline containing $0.1 \%$ Tween 20 (TBST) for 2 hours at room temperature and probed with primary antibodies overnight at $4^{\circ} \mathrm{C}$. The membranes were washed with TBST three times. Then, the membranes were incubated with horseradish peroxidase-conjugated antibody for 1 hour at room temperature. After washing with TBST four times, the membranes were visualized using ECL and Bio-Rad Laboratories. The Western blots shown are representative of at least three independent experiments. Densitometry of each band for the target protein was quantified by densitometry analysis with Scion Image 4.03. The protein band intensity was quantified by the mean \pm SEM of three experiments for each group as determined from the densitometry relative to GAPDH/ $\beta$-actin.

\section{Clone formation assay}

To analyze the effect of bufalin on the clonogenicity of tumor cells in vitro, SW620 and LoVo cell lines (1,000 cells/well) were seeded in six-well plates and treated with different concentrations of bufalin. After 14 days, the cells were washed with PBS and fixed with fixation solution (methanol: glacial acetic: $\mathrm{H}_{2} \mathrm{O}$ 1:1:8) for $10 \mathrm{~min}$, and stained with $0.1 \%$ crystal violet for $30 \mathrm{~min}$. The clones with more than 50 cells were counted under an optical microscope.

\section{Flow Cytometry Analysis}

SW620 and LoVo cells were treated with different concentrations of bufalin, and the cells were collected for propidium iodide (PI) staining. Briefly, the cells were fixed in $70 \%$ ethyl alcohol at $4{ }^{\circ} \mathrm{C}$ overnight, washed with PBS and incubated with RNase $(10 \mathrm{mg} / \mathrm{mL})$ at $37^{\circ} \mathrm{C}$ for $30 \mathrm{~min}$. Next, the cells were incubated with PI ( $5 \mathrm{mg} / \mathrm{mL}$ ) for $30 \mathrm{~min}$ in the dark. The samples were analyzed using a BD ACCURI C6 within 30 min after the staining.

\section{Apoptosis assay}

Apoptosis was assessed by annexin V-binding analysis using flow cytometry. For flow cytometric analysis, cells $\left(4 \times 10^{6}\right)$ were seeded in 6-cm dishes overnight before being treated with various concentrations of bufalin for $48 \mathrm{~h}$. Both adherent and floating cells were harvested and combined, washed twice with PBS, resuspended in $500 \mu \mathrm{l}$ of binding buffer, and stained using an Annexin V-FITC/PI kit according to the manufacturer's instructions. After incubation in the dark for $30 \mathrm{~min}$, the cells were analyzed using BD ACCURI C6.

\section{Acridine orange/ethidium bromide (AO/EB) staining}

LoVo cells were plated in 6-well plates and treated with bufalin $(0,5,10$ and $20 \mathrm{nM})$. After a $48 \mathrm{~h}$ treatment, $10 \mu \mathrm{l}$ of the AO/EB dye mix $(100 \mu \mathrm{g} / \mathrm{ml}$ of AO and $100 \mu \mathrm{g} / \mathrm{ml}$ of EB in PBS) was added to each well. The apoptotic, necrotic and live cells were observed and counted under a fluorescence microscope (IX81, Olympus).

\section{Scratch wound assay}

Cells were seeded into six-well plates and then cultured to $90 \%$ confluence. The confluent cell monolayer was wounded using a sterile $200 \mu \mathrm{l}$ pipette tip. The suspended cells were washed using normal growth medium. The scratch wound was photographed after $72 \mathrm{~h}$ using a DMI4000B, Leica microscope in three fields of view at $100 \times$ magnification. The area of the open wound was quantified using Photoshop (Adobe). 


\section{Cellular Physiology Cell Physiol Biochem 2016;40:1559-1569 \begin{tabular}{l|l|l} 
and Biochemistry & DOI: 10.1159/000453206 & $\begin{array}{l}\text { (c) } 2016 \text { The Author(s). Published by S. Karger AG, Basel } \\
\text { www.karger.com/cpb }\end{array}$
\end{tabular} \\ Zhang et al.: Bufalin Inhibits Colorectal Cancer Cells Growth}

\section{Streptavidin-agarose pulldown assay}

Transactivators binding to an hTERT core promoter probe were determined by a streptavidin-agarose pulldown assay. Briefly, a biotin-labeled double-stranded DNA probe corresponding to nucleotides -378 to -159 bp of the hTERT promoter sequence was synthesized by Sigma (Sigma-Aldrich, St. Louis, MO) (sense, 5'-ACC CTG GGA GCG CGA GCG GC-3'; antisense, 5'-GGG GCG GGG TCC GCG CGG AG-3'). Then, $500 \mu \mathrm{g}$ of nuclear protein extract, $4 \mu \mathrm{g}$ of DNA probe and $40 \mu \mathrm{l}$ of streptavidin-agarose beads (Sigma-Aldrich) were mixed and incubated at room temperature for $2 \mathrm{~h}$ on a rotating shaker and then pelleted by centrifugation to pull down the DNA-protein complex. After washing with cold phosphate-buffered saline (PBS), proteins in the complex were analyzed.

\section{Chromatin immunoprecipitation (ChIP)}

Cells were fixed with $1 \%$ formaldehyde and sonicated to shear the DNA to $200 \mathrm{bp}$ to $500 \mathrm{bp}$ on ice. One third of the total cell lysate was used as the DNA input control. The remaining two thirds of the total lysate were subjected to immunoprecipitation with anti-CPSF4 antibody or non-immune rabbit IgG. The DNA was subjected to PCR to amplify a $220 \mathrm{bp}$ region $(-378$ to $-159 \mathrm{bp}$ ) of the hTERT promoter using primers (sense, 5'-ACC CTG GGA GCG CGA GCG GC-3'; antisense, 5'-GGG GCG GGG TCC GCG CGG AG-3'). The PCR products were resolved electrophoretically on a $1 \%$ agarose gel and visualized by ethidium bromide staining.

Promoter reporters and luciferase assay

Cells $\left(2 * 10^{5}\right.$ cells/well) were seeded into six-well plates, cultured overnight, and transfected with hTERT promoter luciferase plasmids or a GFP reporter vector (driven by a CMV or an hTERT promoter) ( 2 $\mu \mathrm{g}$ per well of plasmid) with Lipofectamine 3000 (Invitrogen, Carlsbad, CA). Meanwhile, cells were treated with different concentrations of bufalin. The luciferase activity was assayed using the Luciferase reporter assay system Enspire2300, Perkin Elmer.

\section{Statistical analyses}

Data were expressed as the mean \pm SEM of three independent experiments with GraphPad Prism software. The Student's t-test was used to make a statistical comparison between groups. ${ }^{*} P<0.05$ was considered statistically significant.

\section{Results}

Bufalin inhibited the proliferation of SW620 cells

Bufalin can effectively inhibit cell proliferation in various common human cancer cell lines. Previous studies have shown that bufalin inhibits the proliferation of leukemia [6], prostate cancer [5], gastric cancer [25], and osteosarcoma [26]. Therefore, we investigated whether bufalin could also inhibit cell proliferation in SW620 cells. The structure of bufalin is shown in Fig. 1. The results showed that bufalin decreased cell viability in a dose- $(0,5,10,20,30$, 40, $50 \mathrm{nM}$ ) and time- $(0,24,48,72,96 \mathrm{~h})$ dependent manner in SW620 (Fig. 2A) cells by CCK-8. The IC ${ }_{50}$ values were $287.35 \pm 4.34(24 \mathrm{~h}), 57.63 \pm 7.80(48 \mathrm{~h}), 20.39 \pm 1.95(72 \mathrm{~h})$, and $12.07 \pm 1.73(96 \mathrm{~h})$. Then, SW620 cells were treated with bufalin at different concentrations $(0,10,20,50 \mathrm{nM})$ for $48 \mathrm{~h}$. We observed that bufalin could inhibit SW620 cell proliferation by colony forming assay (Fig. 2B) and Western blotting (Fig. 2C). Flow cytometry was used to detect the effect of bufalin on cell cycle distribution in SW620 cells. As shown in Fig. $2 \mathrm{D}$, bufalin treatment at $50 \mathrm{nM}$ arrested most cells at $\mathrm{G} 2 / \mathrm{M}$ phase and significantly reduced cells at G0/G1 phases.

Bufalin inhibited the proliferation of LoVo cells

We also investigated whether bufalin could inhibit proliferation in LoVo cells. The

Fig. 1. Structure of bufalin.

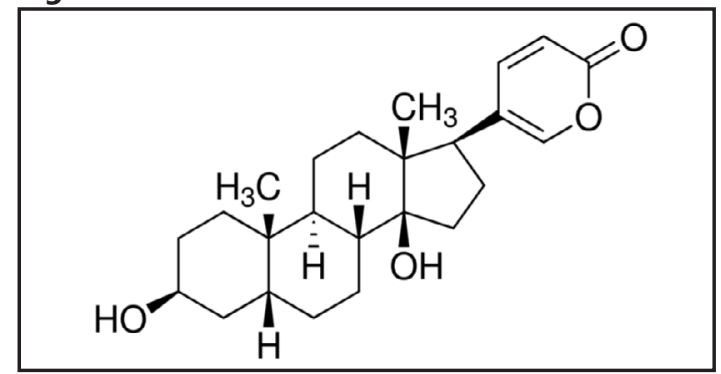




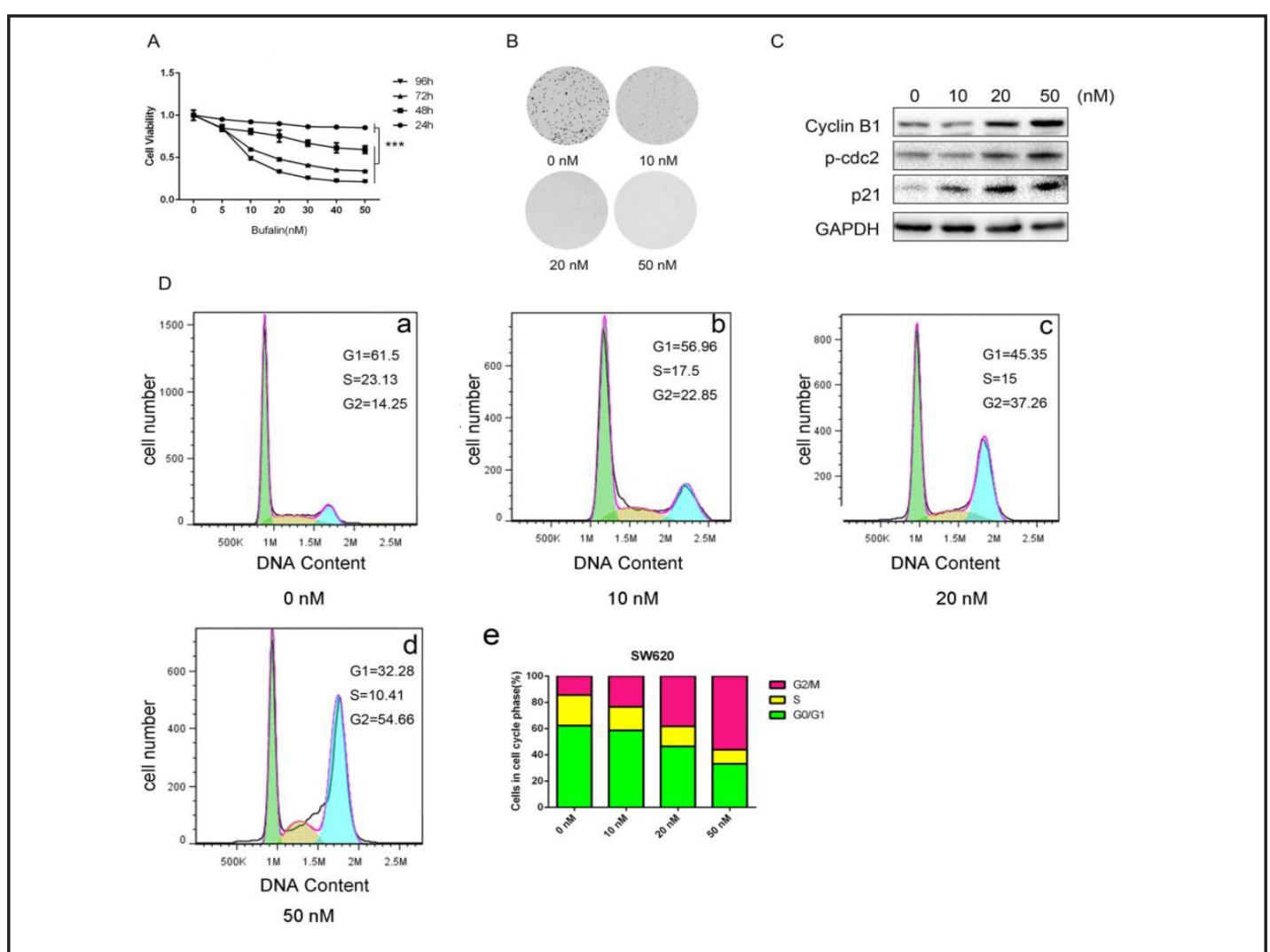

Fig. 2. Bufalin inhibits SW620 cell proliferation. (A) SW620 cells were treated with bufalin (0, 5, 10, 20, 30, 40 and $50 \mathrm{nM}$ ) for $24 \mathrm{~h}, 48 \mathrm{~h}, 72 \mathrm{~h}$ and $96 \mathrm{~h}$. Cell viability was determined by CCK-8 assay as described in the Materials and methods. (B) Colony formation assay of SW620 cells. Cells were grown in the absence or presence of bufalin at the indicated concentrations $(0,10,20$ and $50 \mathrm{nM})$ for 2 weeks. Cells were fixed and stained with crystal violet. (C) Western blotting was employed to examine cyclin B1, p-cdc2 and p21 protein expression in SW620 cells. GAPDH was used as an internal control. (D) Flow cytometry analysis was performed on the SW620 cells that were treated with bufalin $(0,10,20$ and $50 \mathrm{nM})$.

results showed that bufalin decreased cell viability in a dose- $(0,5,10,20,30,40,50 \mathrm{nM})$ and time- $(0,24,48,72,96 \mathrm{~h})$ dependent manner in LoVo (Fig. $3 \mathrm{~A})$ cells by CCK-8. The $\mathrm{IC}_{50}$ values were $56.778 \pm 7.34(24 \mathrm{~h}), 11.48 \pm 2.89(48 \mathrm{~h}), 6.64 \pm 2.79(72 \mathrm{~h})$, and $6.00 \pm 0.54(96 \mathrm{~h})$. Then, LoVo cells were treated with bufalin at different concentrations $(0,5,10,20 \mathrm{nM})$ for $48 \mathrm{~h}$. We observed that bufalin could inhibit LoVo cell proliferation by colony forming assay (Fig. 3B) and Western blotting (Fig. 3C). Flow cytometry was used to detect the effect of bufalin on cell cycle distribution in LoVo cells. As shown in Fig. 3D, bufalin treatment at $20 \mathrm{nM}$ arrested most cells at G2/M phase and significantly reduced cells at G0/G1 phases.

\section{Bufalin induces colorectal cell apoptosis}

With the increasing concentration of bufalin used to treat SW620 and LoVo cells, the morphology of SW620 (Fig. 4A) and LoVo (Fig. 4B) cells changed. Representative results of the annexin V-FITC/PI double-labeled flow cytometry analysis of apoptosis are shown in Fig. 4C and Fig. 4D. Bufalin could induce apoptosis in SW620 and LoVo cells after a $48 \mathrm{~h}$ treatment in a concentration-dependent manner. AO/EB double fluorescent staining was performed to observe the apoptotic morphology of the cancer cells. As shown in Fig. 4E, after treatment with bufalin, the morphology of LoVo cells included nuclear condensation, membrane blebbing, nuclear fragmentation and apoptotic bodies, all of which are characteristics of apoptotic programmed cell death. To further examine the effect of inducing apoptosis by bufalin, the expression of apoptosis-related proteins (PARP, Bax, Bcl-2, cleaved caspase 7 and cleaved 
A

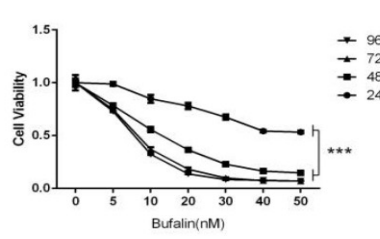

$\mathrm{D}$
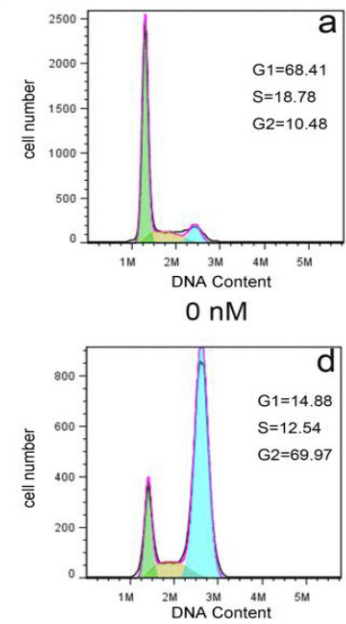

$10 \mathrm{nM}$

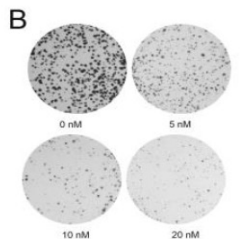

C
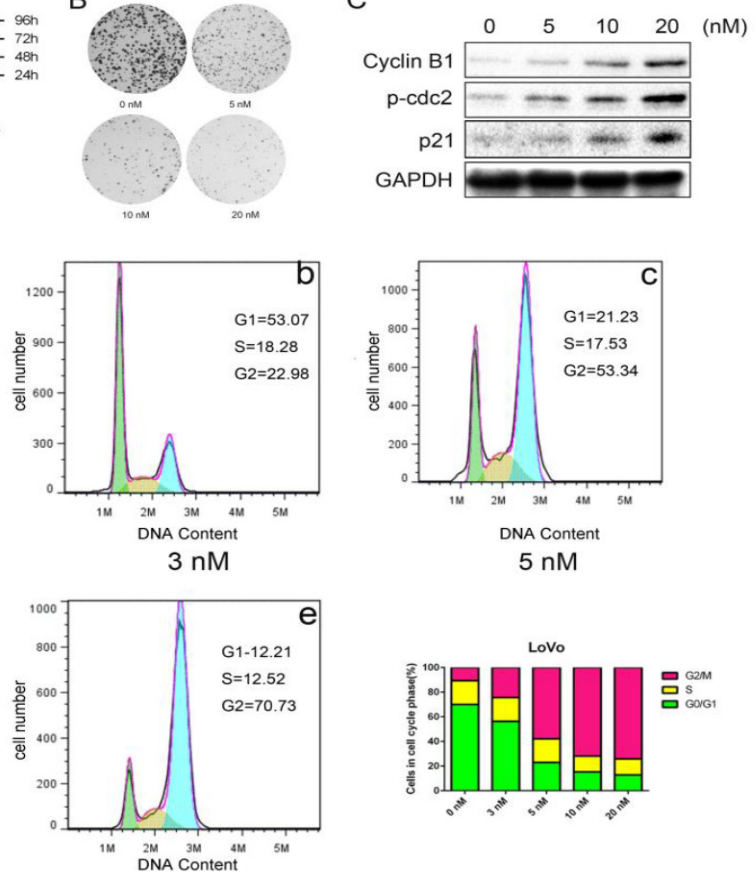

$20 \mathrm{nM}$

Fig. 3. Bufalin inhibits LoVo cell proliferation. (A) LoVo cells were treated with bufalin (0, 5, 10, 20, 30, 40 and $50 \mathrm{nM}$ ) for $24 \mathrm{~h}, 48 \mathrm{~h}, 72 \mathrm{~h}$ and $96 \mathrm{~h}$. Cell viability was determined by CCK- 8 assay as described in the Materials and methods. (B) Colony formation assay of LoVo cells. Cells were grown in the absence or presence of bufalin at the indicated concentrations $(0,5,10$ and $20 \mathrm{nM})$ for 2 weeks. Cells were fixed and stained with crystal violet. (C) Western blotting was employed to examine cyclin B1, p-cdc2 and p21 protein expression in LoVo cells. GAPDH was used as an internal control. (D) Flow cytometry analysis was performed on the LoVo cells that were treated with bufalin $(0,3,5,10$ and $20 \mathrm{nM})$.

caspase 9) were evaluated. As shown in Fig. 4F, with the increasing concentration of bufalin used to treat LoVo cells, the expression of Bcl-2 was decreased. Conversely, the expression of PARP, Bax, cleaved caspase 7 and cleaved caspase 9 were significantly upregulated.

\section{Bufalin inhibits colorectal cell migration}

To determine whether bufalin influenced colorectal cell migration, LoVo cells were treated with bufalin at $0 \mathrm{nM}, 5 \mathrm{nM}, 10 \mathrm{nM}$ and $20 \mathrm{nM}$ for $72 \mathrm{~h}$. We used a scratch wound assay to detect the migration ability of LoVo. We found that bufalin could inhibit LoVo migration (Fig. 5A and 5B). Then, LoVo and SW620 cells were treated with bufalin at different concentrations for $48 \mathrm{~h}$, and the expression of $\mathrm{N}$-cadherin, E-cadherin and $\beta$-catenin were detected by Western blot. The results indicated that bufalin could inhibit the expression of $\mathrm{N}$-cadherin and $\beta$-catenin, and promote E-cadherin expression (Fig. $5 \mathrm{C}$ ).

\section{Bufalin decreases the expression of hTERT by inhibiting CPSF4}

The CPSF4 protein promotes the expression of hTERT and telomerase activity in lung cancer cell lines; therefore, we wanted to determine whether CPSF4 protein promotes the expression of hTERT in colorectal cancer cell lines. First, we used different concentrations of bufalin treatment on LoVo and SW620 cells. The results showed that the expression of CPSF4 and hTERT was inhibited by bufalin in a dose-dependent manner in LoVo and SW620 cells (Fig. 6A and 6B). To verify CPSF4 as an hTERT promoter-binding protein, we analyzed the binding of CPSF4 to the hTERT promoter using a ChIP assay with a specific antibody against CPSF4. Normal IgG was used as a negative control. As shown in Fig. 6C and 6D, the hTERT 


\section{Cellular Physiology Cell Physiol Biochem 2016;40:1559-1569 \begin{tabular}{ll|l} 
DOI: 10.1159/000453206 & O 2016 The Author(s). Published by S. Karger AG, Basel \\
and Biochemistry & Published online: Decemer 21, 2016 & www.karger.com/cpb
\end{tabular}

Fig. 4. Bufalin induces SW620 and LoVo cell apoptosis. (A) The morphology of SW620 cells with bufalin treatment $(0$, 10,20 and $50 \mathrm{nM}$ ); (B) the morphology of LoVo cells with bufalin treatment $(0$, 5, 10 and $20 \mathrm{nM}$ ); (C) SW620 cells were double stained with annexin V/PI and analyzed by FACS analysis after a $48 \mathrm{~h}$ treatment with bufalin $(0,10$ and $30 \mathrm{nM})$. The percentage of annexin V+/PI- (early apoptotic cells, lower right), annexin V+/PI+ (late apoptotic cells, upper right), annexin V-/ PI- (viable cells, lower left) and annexin V-/PI+ (necrotic cells, upper left) cells is shown. (D) LoVo cells were double stained with annexin V/PI and analyzed by FACS analysis after a $48 \mathrm{~h}$ treatment with bufalin $(0,5$ and 10

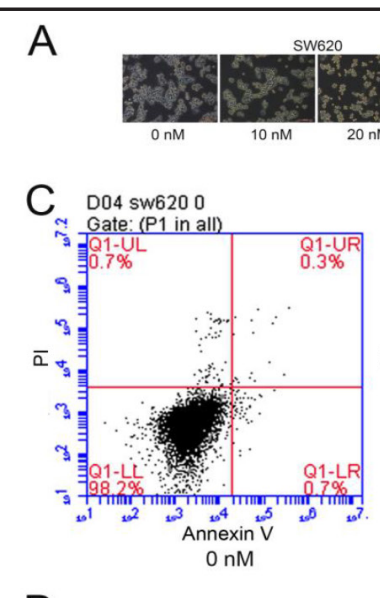

D

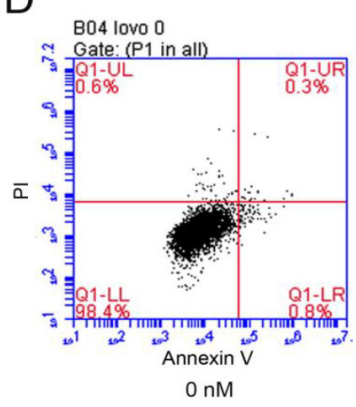

$\mathrm{E}$
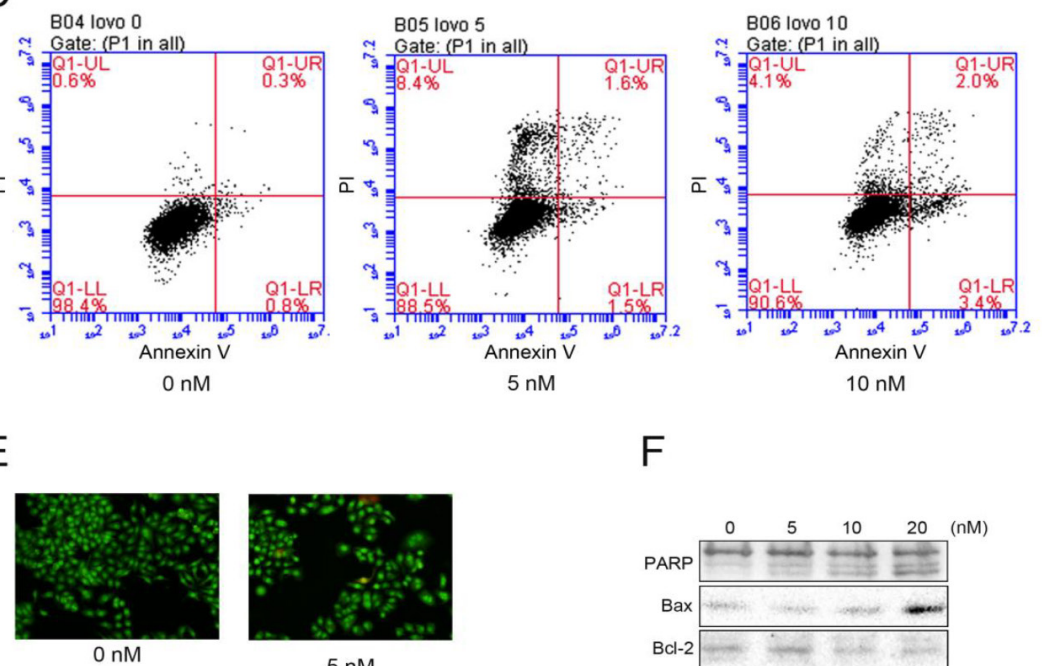

$\mathrm{O} \mathrm{nM}$

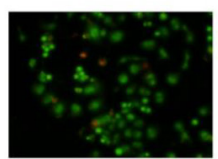

$10 \mathrm{nM}$
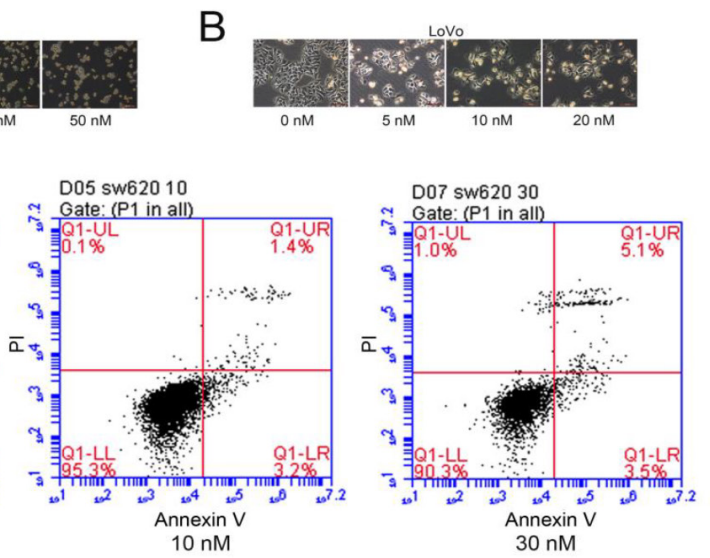

$\mathrm{F}$

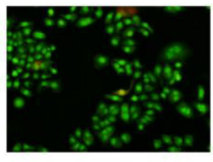

$5 \mathrm{nM}$



$20 \mathrm{nM}$

$\mathrm{nM}$ ). The percentage of annexin V+/PI- (early apoptotic cells, lower right), annexin V+/PI+ (late apoptotic cells, upper right), annexin V-/PI- (viable cells, lower left) and annexin V-/PI+ (necrotic cells, upper left) cells is shown. (E) AO/EB double fluorescent staining of the LoVo cells treated with different concentrations of bufalin (0, 5, 10 and $20 \mathrm{nM}$ ) for $48 \mathrm{~h}$. (F) LoVo cells were treated with bufalin $(0,5,10$ and $20 \mathrm{nM})$ for $48 \mathrm{~h}$. The expression levels of PARP, caspase-9, 7, Bcl-2, and Bax were analyzed by Western blot analysis, bar $=100 \mu \mathrm{m}$.

promoter was amplified in LoVo and SW620 cells, indicating that CPSF4 was bound to the hTERT promoter. To further confirm the binding of CPSF4 to the hTERT promoter region in CRC cells, we performed immunoblot analyses of the proteins eluted from the biotinstreptavidin pulldown complexes using an anti-CPSF4 antibody. As shown in Fig. 6E and 6F, CPSF4 was clearly detected in the complexes prepared from the human CRC cell lines LoVo and SW620. Then, cells were transfected with a luciferase reporter and treated with bufalin. Luciferase activity was measured in LoVo (Fig. 6G) and SW620 (Fig. 6H) cells. The results showed that the Luciferase activity of hTERT was inhibited by bufalin in a dose-dependent manner in LoVo and SW620 cells. To further study the role of relationship among in bufalin, CPSF4 and hTERT expression, the overexpression plasmid of CPSF4 was transfected to cells. 


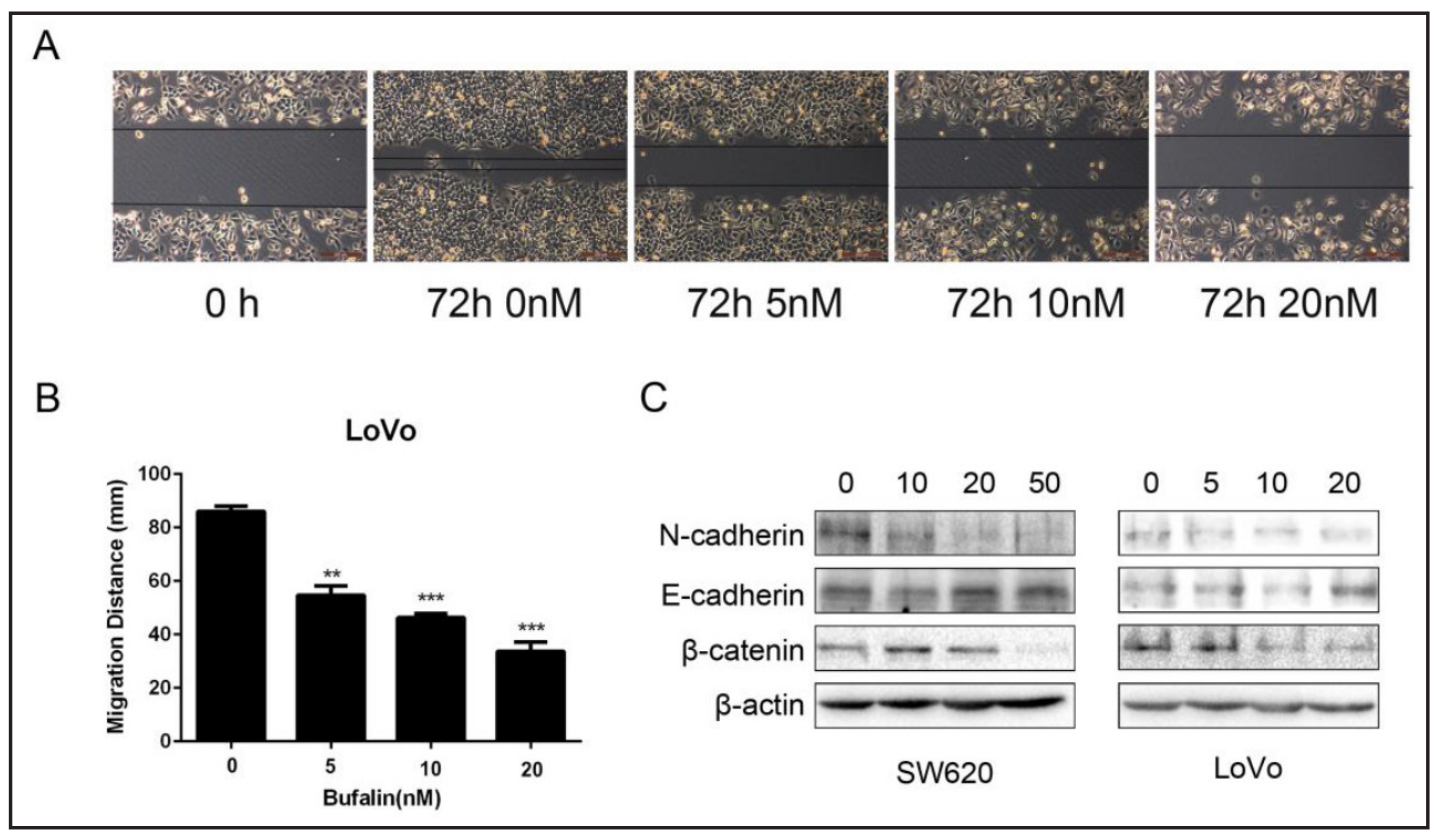

Fig. 5. Bufalin inhibits LoVo and SW620 cell migration. (A, B) Cells were seeded in 6-well plates, and LoVo cell migration was detected by a scratch wound assay. (C) LoVo and SW620 cells were treated with bufalin at different concentrations $\mathrm{nM}$ for $72 \mathrm{~h}$. Western blot was used to detect the expression of E-cadherin, $\beta$-catenin and $\mathrm{N}$-cadherin, bar $=100 \mu \mathrm{m}$.

As shown in Fig. 6I, the expression of CPSF4 were significantly increased after plasmid transfected compared with control cells. After transient transfection for $24 \mathrm{~h}$, LoVo cells transfected with CPSF4 overexpression plasmid were monitored under a fluorescent microscope (Fig. 6J).Then we detected the expression and Luciferase activity of hTERT after plasmid and bufalin treated with LoVo cells at the same time. As shown in Fig.6K and 6L, cells transfected with CPSF plasmid had higher Luciferase activity and levels of hTERT expression compared with cells transfected with the control plasmids. While the cells cotransfected with CPSF plasmid and bufalin treatment showed lower Luciferase activity and hTERT expression level compared with the cells transfected with CPSF plasmid.

\section{Discussion}

CRC is one of the most common causes of cancer death [27]. Bufalin has been reported to play a critical role in cancer cell apoptosis and differentiation in ovarian and prostate cancer $[28,29]$, with little toxic effect on normal cells at low doses. Bufalin also induces the generation of ROS in lung cancer [30]. However, the role of bufalin in colorectal cancer cell lines has not been thoroughly investigated. In our study, a dose- and time-dependent growth inhibition was observed in the CCK-8 assay and clone formation assay when cells were treated with bufalin. By flow cytometry analysis, we observed that bufalin could arrest most cells at G2/M phase in LoVo and SW620 cells. We determined that bufalin could also promote apoptosis and inhibit the migration of LoVo and SW620 cells. These results may be significant in understanding the role of bufalin in treating colorectal cancer.

Increasing numbers of studies have demonstrated a strong correlation between elevated hTERT expression and activation and CRC, and hTERT is thought to be a potential therapeutic target for cancer therapy. Therefore, the molecular mechanisms of hTERT in CRC must be identified. Additionally, it is known that over-activation of hTERT leads to telomere lengthening and cell immortalization, playing a crucial role in tumorigenesis and development. Conversely, degradation of hTERT by proteasomes or repression of its activity 


\section{Cellular Physiology Cell Physiol Biochem 2016;40:1559-1569

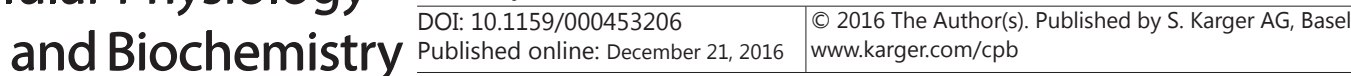 \\ Zhang et al.: Bufalin Inhibits Colorectal Cancer Cells Growth}

Fig. 6. Bufalin reduces hTERT expression and inhibits CPSF4 binging to the hTERT promoter. The expression of hTERT and CPSF4 were detected by Western blotting in LoVo (A) and SW620 (B) cells after treatment with different concentrations of bufalin for 48 h. Binding of CPSF4 to a biotinylated hTERT promoter probe (-378 to -159 bp). Chromatin immunoprecipitation assays were performed using the hTERT promoter in LoVo (C) and SW620 (D) cells. CPSF4 proteins in the nuclear protein-hTERT probe-streptavidin bead complexes were detected by Western blot using an anti-CPSF4 antibody in LoVo (E) and SW620 (F) cells. Cells were transfected with a luciferase reporter and treated with bufalin. The luciferase activity was measured in LoVo (G) and SW620 (H) cells. (I) Protein levels of CPSF4 by Western blot after overexpression plasmid of CPSF4 transfected in LoVo cells. (J) LoVo cells transfected with plasmid were monitored under a fluorescent microscope. (bar $=50 \mu \mathrm{m})(\mathrm{K})$ Protein levels of hTERT by Western blot was measured in LoVo after overexpression plasmid of CPSF4 transfected and bufalin treated. (L) The luciferase activity was measured in LoVo after overexpression plasmid of CPSF4 transfected and bufalin treated.
A

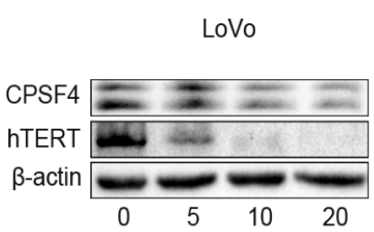

C

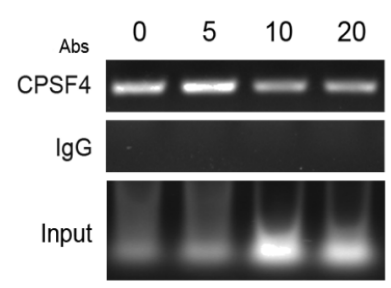

$E$

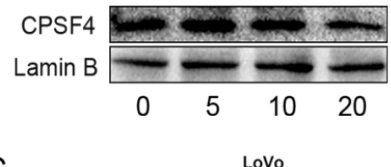

G

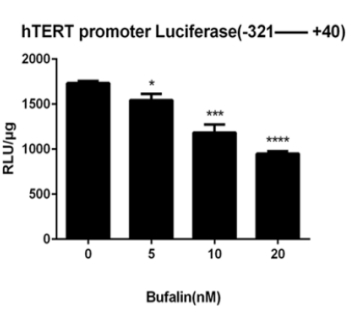

I

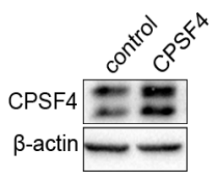

$\mathrm{K}$

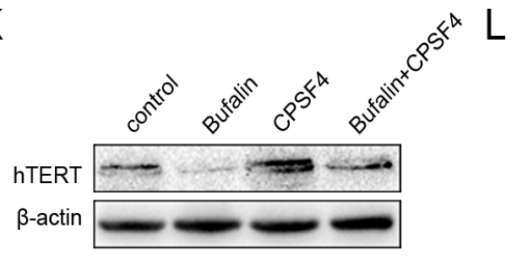

B

SW620

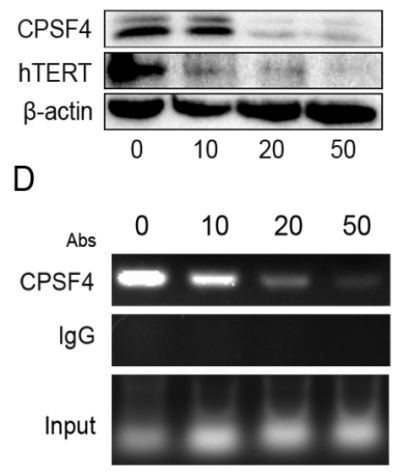

F

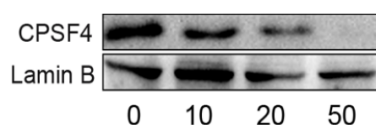

$\mathrm{H}$
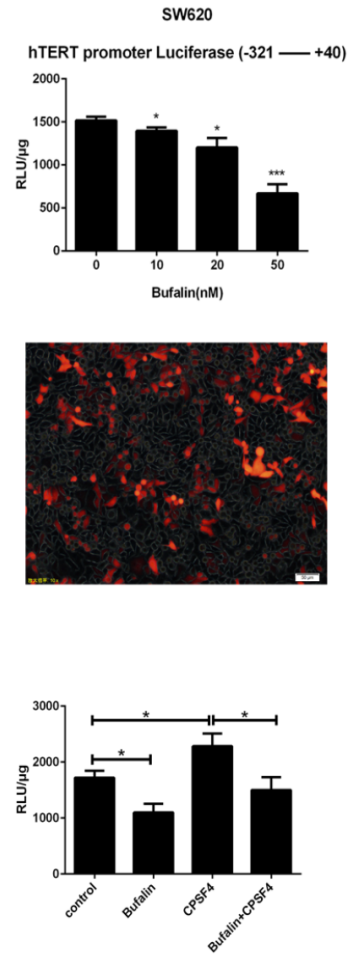

prompts telomere shortening, cancer cell senescence, and apoptosis. The expression of hTERT can be regulated by promoter methylation or chromatin remodeling [31,32], as well as by activators and repressors, such as USF1/2, Sp1, TGF- $\beta$, p53 and c-Myc[33-35].

CPSF4 can inhibit the nuclear export of cellular mRNAs [36]. However, its other biological functions have rarely been reported. CPSF4 was overexpressed in lung adenocarcinomas and participated in lung cancer cell growth [21]. In addition, CPSF4 could be a transcriptional factor that activates hTERT in lung cancer cells [24].

Based on the above reports, we considered the hypothesis that bufalin could inhibit the expression of CPSF 4 and CPSF4 may be associated with the activation of hTERT transcription. Pulldown, ChIP and luciferase assays were performed after LoVo and SW620 cells were 


\section{Cellular Physiology Cell Physiol Biochem 2016;40:1559-1569

 \\ Zhang et al.: Bufalin Inhibits Colorectal Cancer Cells Growth}

treated with bufalin. We determined that bufalin could decrease the expression of CPSF4 and hTERT, and CPSF4 was a transcriptional factor that could activate hTERT.

In summary, we found that bufalin was a potent inhibitory agent in proliferation and migration in colorectal cancer cells while promoting apoptosis. Bufalin inhibited the expression of hTERT by down-regulating CPSF4. Our results provide a mechanism linking bufalin, CPSF4 and hTERT, and may provide support for the development of therapeutic strategies for cancer therapy.

\section{Acknowledgments}

This work was supported by funds from the National Natural Science Foundation of China (81173615 XC, 81472178 WD), Science and technique support plane of the First Affiliated Hospital of Dalian Medical University (2013D005), the State "973 Program" of China (2014CB542005), the Education Department of Liaoning Province in China (the "Program for Pan-Deng Scholars"), and the National Natural Science Foundation of Liaoning Province in China.

\section{Disclosure Statement}

None of the authors listed in this manuscript have a conflict of interest.

\section{References}

1 Brenner H, Kloor M, Pox CP: Colorectal cancer. Lancet 2014;383:1490-1502.

2 Wang X, Kuang YY, Hu XT: Advances in epigenetic biomarker research in colorectal cancer. World J Gastroenterol 2014;20:4276-4287.

3 Meng Z, Yang P, Shen Y, Bei W, Zhang Y, Ge Y, Newman RA, Cohen L, Liu L, Thornton B, Chang DZ, Liao Z, Kurzrock R: Pilot study of huachansu in patients with hepatocellular carcinoma, nonsmall-cell lung cancer, or pancreatic cancer. Cancer-Am Cancer Soc 2009;115:5309-5318.

4 Han KQ, Huang G, Gu W, Su YH, Huang XQ, Ling CQ: Anti-tumor activities and apoptosis-regulated mechanisms of bufalin on the orthotopic transplantation tumor model of human hepatocellular carcinoma in nude mice. World J Gastroenterol 2007;13:3374-3379.

5 Yeh JY, Huang WJ, Kan SF, Wang PS: Effects of bufalin and cinobufagin on the proliferation of androgen dependent and independent prostate cancer cells. Prostate 2003;54:112-124.

6 Watabe M, Ito K, Masuda Y, Nakajo S, Nakaya K: Activation of ap-1 is required for bufalin-induced apoptosis in human leukemia u937 cells. Oncogene 1998;16:779-787.

7 Wang J, Yin JQ Jia Q Shen JN, Huang G, Xie XB, Zou CY: [bufalin induces apoptosis in osteosarcoma u-2os and u-2os methotrexate 300-resistant cell lines in vitro]. Zhonghua Zhong Liu Za Zhi 2010;32:734-738.

8 Chang Y, Zhao Y, Gu W, Cao Y, Wang S, Pang J, Shi Y: Bufalin inhibits the differentiation and proliferation of cancer stem cells derived from primary osteosarcoma cells through mir-148a. Cell Physiol Biochem 2015;36:1186-1196.

9 Li D, Qu X, Hou K, Zhang Y, Dong Q Teng Y, Zhang J, Liu Y: Pi3k/akt is involved in bufalin-induced apoptosis in gastric cancer cells. Anticancer Drugs 2009;20:59-64.

10 Zhu Z, Li E, Liu Y, Gao Y, Sun H, Ma G, Wang Z, Liu X, Wang Q, Qu X, Liu Y, Yu Y: Inhibition of jak-stat3 pathway enhances bufalin-induced apoptosis in colon cancer sw620 cells. World J Surg Oncol 2012;10:228.

11 Xie CM, Chan WY, Yu S, Zhao J, Cheng CH: Bufalin induces autophagy-mediated cell death in human colon cancer cells through reactive oxygen species generation and jnk activation. Free Radic Biol Med 2011;51:1365-1375.

12 Qiu YY, Hu Q, Tang QF, Feng W, Hu SJ, Liang B, Peng W, Yin PH: Microrna-497 and bufalin act synergistically to inhibit colorectal cancer metastasis. Tumour Biol 2014;35:2599-2606. 


\section{Cellular Physiology Cell Physiol Biochem 2016;40:1559-1569

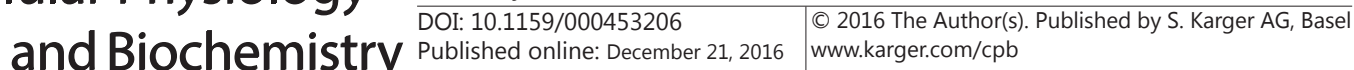 \\ Zhang et al.: Bufalin Inhibits Colorectal Cancer Cells Growth}

13 Cong YS, Wright WE, Shay JW: Human telomerase and its regulation. Microbiol Mol Biol Rev 2002;66:407425.

14 Blasco MA: Telomeres and cancer: a tale with many endings. Curr Opin Genet Dev 2003;13:70-76.

15 Chen CH, Chen RJ: Prevalence of telomerase activity in human cancer. J Formos Med Assoc 2011;110:275289.

16 Lam AK, Saleh S, Smith RA, Ho YH: Quantitative analysis of survivin in colorectal adenocarcinoma: increased expression and correlation with telomerase activity. Hum Pathol 2008;39:1229-1233.

17 Vidaurreta M, Maestro ML, Rafael S, Veganzones S, Sanz-Casla MT, Cerdan J, Arroyo M: Telomerase activity in colorectal cancer, prognostic factor and implications in the microsatellite instability pathway. World J Gastroenterol 2007;13:3868-3872.

18 Saleh S, Lam AK, Ho YH: Real-time pcr quantification of human telomerase reverse transcriptase (htert) in colorectal cancer. Pathology 2008;40:25-30.

19 Tamakawa RA, Fleisig HB, Wong JM: Telomerase inhibition potentiates the effects of genotoxic agents in breast and colorectal cancer cells in a cell cycle-specific manner. Cancer Res 2010;70:8684-8694.

20 Kaufmann I, Martin G, Friedlein A, Langen H, Keller W: Human fip1 is a subunit of cpsf that binds to u-rich rna elements and stimulates poly(a) polymerase. Embo J 2004;23:616-626.

21 Chen W, Guo W, Li M, Shi D, Tian Y, Li Z, Wang J, Fu L, Xiao X, Liu QQ, Wang S, Huang W, Deng W: Upregulation of cleavage and polyadenylation specific factor 4 in lung adenocarcinoma and its critical role for cancer cell survival and proliferation. Plos One 2013;8:e82728.

22 Rozenblatt-Rosen O, Nagaike T, Francis JM, Kaneko S, Glatt KA, Hughes CM, LaFramboise T, Manley JL, Meyerson M: The tumor suppressor cdc73 functionally associates with cpsf and cstf 3' mrna processing factors. Proc Natl Acad Sci U S A 2009;106:755-760.

23 Yi C, Wang Y, Zhang C, Xuan Y, Zhao S, Liu T, Li W, Liao Y, Feng X, Hao J, Gao Y, Yu W, Chen Y, Zhang C, Guo W, Tang B, Deng W: Cleavage and polyadenylation specific factor 4 targets nf-kappab/cyclooxygenase-2 signaling to promote lung cancer growth and progression. Cancer Lett 2016;381:1-13.

24 Chen W, Qin L, Wang S, Li M, Shi D, Tian Y, Wang J, Fu L, Li Z, Guo W, Yu W, Yuan Y, Kang T, Huang W, Deng W: Cpsf4 activates telomerase reverse transcriptase and predicts poor prognosis in human lung adenocarcinomas. Mol Oncol 2014;8:704-716.

25 Li A, Qu X, Li Z, Qu J, Song N, Ma Y, Liu Y: Secreted protein acidic and rich in cysteine antagonizes bufalininduced apoptosis in gastric cancer cells. Mol Med Rep 2015;12:2926-2932.

26 Yin JQ, Shen JN, Su WW, Wang J, Huang G, Jin S, Guo QC, Zou CY, Li HM, Li FB: Bufalin induces apoptosis in human osteosarcoma u-2os and u-2os methotrexate300-resistant cell lines. Acta Pharmacol Sin 2007;28:712-720.

27 Bray F, Ren JS, Masuyer E, Ferlay J: Global estimates of cancer prevalence for 27 sites in the adult population in 2008. Int J Cancer 2013;132:1133-1145.

28 Takai N, Ueda T, Nishida M, Nasu K, Narahara H: Bufalin induces growth inhibition, cell cycle arrest and apoptosis in human endometrial and ovarian cancer cells. Int J Mol Med 2008;21:637-643.

29 Yu CH, Kan SF, Pu HF, Jea CE, Wang PS: Apoptotic signaling in bufalin- and cinobufagin-treated androgendependent and -independent human prostate cancer cells. Cancer Sci 2008;99:2467-2476.

30 Sun L, Chen T, Wang X, Chen Y, Wei X: Bufalin induces reactive oxygen species dependent bax translocation and apoptosis in astc-a-1 cells. Evid Based Complement Alternat Med 2011;2011:249090.

31 Guilleret I, Yan P, Grange F, Braunschweig R, Bosman FT, Benhattar J: Hypermethylation of the human telomerase catalytic subunit (htert) gene correlates with telomerase activity. Int J Cancer 2002;101:335341.

32 Kyo S, Takakura M, Fujiwara T, Inoue M: Understanding and exploiting htert promoter regulation for diagnosis and treatment of human cancers. Cancer Sci 2008;99:1528-1538.

33 Goueli BS, Janknecht R: Regulation of telomerase reverse transcriptase gene activity by upstream stimulatory factor. Oncogene 2003;22:8042-8047.

34 Poole JC, Andrews LG, Tollefsbol TO: Activity, function, and gene regulation of the catalytic subunit of telomerase (htert). Gene 2001;269:1-12.

35 Renaud S, Loukinov D, Bosman FT, Lobanenkov V, Benhattar J: Ctcf binds the proximal exonic region of htert and inhibits its transcription. Nucleic Acids Res 2005;33:6850-6860.

36 Nemeroff ME, Barabino SM, Li Y, Keller W, Krug RM: Influenza virus ns1 protein interacts with the cellular 30 kda subunit of cpsf and inhibits 3'end formation of cellular pre-mrnas. Mol Cell 1998;1:991-1000. 